\title{
P287: Adherence to biosafety practices by nursing staff in the face of situations of occupational risk
}

\author{
PB Santos ${ }^{1 *}$, MS Moraes ${ }^{2}$, ACDS Oliveira ${ }^{3}$, S Scotá ${ }^{3}$, AS Gomes ${ }^{1}$, SR Moura', RS Martins ${ }^{1}$ \\ From 2nd International Conference on Prevention and Infection Control (ICPIC 2013) \\ Geneva, Switzerland. 25-28 June 2013
}

\section{Introduction}

The nursing staff is more susceptible to biological hazards in health services, due to the greater frequency of patient contact. Thus, preventive measures to contagion and spread of disease are essential to provide safe care.

\section{Objectives}

To assess the knowledge and use of Personal Protective Equipment (PPE), as well as the biosafety measures taken by the nursing staff, and the factors interfering in the exercise of such practices.

\section{Methods}

This was an observational, non-experimental, quantitative, cross-sectional, developed at the Institute of Infectious Diseases Emilio Ribas, reference hospital care to infectious diseases. The study population consisted of 52 professionals, including nurses and nursing assistants who worked in one of four adult patient units.

\section{Results}

$73,1 \%$ (38), followed by isolation aerosols, $65,4 \%$ (34), being a significant index of professionals joined the use of respirator mask type, $89.7 \%$ (52). Regarding the isolation of contact using gloves and apron simultaneously, showed low adhesion to $10.5 \%$ (2) 19 uses observation opportunities. Between the professionals, 25\% (13), assumed that do not use PPE at some point in their activities, the main reasons are the discomfort / difficulty breathing, $30.7 \%(4)$, and the gloves because they decrease the sensitivity, $30.7 \%$ (4). With regard to hand hygiene there was a low uptake in these three conditions: $11.13 \%$ (6), before contact with patients, $57.6 \%$ (45), after contact, and 52, 3\% (11) after removal of gloves.

\section{Conclusion}

Despite having knowledge about the need for the use of PPE in the appropriate caution by contact, professionals had attitudes incompatible with the aforementioned. In the case of isolation by spray gave a significant value for people who know $65.4 \%$ (34) and adhere to the mask respirator type $89.7 \%$ (52). Regarding hand washing, there was obtained an index unsatisfactory.

\section{Competing interests}

None declared.

\section{Author details}

${ }^{1}$ Aprimoramento Profissional, Institute of Infectious Diseases Emilio Ribas, São Paulo, Brazil. '2Diretoria de enfermagem, Institute of Infectious Diseases Emilio Ribas, São Paulo, Brazil. ${ }^{3}$ Educação Continuada e CCIH, Institute of Infectious Diseases Emilio Ribas, São Paulo, Brazil.

Published: 20 June 2013

\section{doi:10.1186/2047-2994-2-S1-P287}

Cite this article as: Santos et al:: P287: Adherence to biosafety practices by nursing staff in the face of situations of occupational risk. Antimicrobial Resistance and Infection Control 2013 2(Suppl 1):P287.

${ }^{1}$ Aprimoramento Profissional, Institute of Infectious Diseases Emilio Ribas, São Paulo, Brazil

Full list of author information is available at the end of the article

(c) 2013 Santos et al; licensee BioMed Central Ltd. This is an Open Access article distributed under the terms of the Creative Commons 